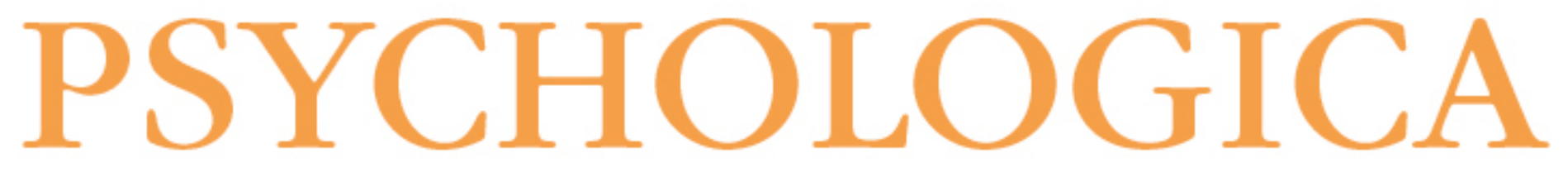

\title{
A líderança dos diretores no contexto educativo português: a ética e a moral, quais as competências e tendências?
}

Autor(es): $\quad$ Neves, Lurdes; Coimbra, Joaquim Luís

Publicado por: Imprensa da Universidade de Coimbra

URL

persistente: URI:http://hdl.handle.net/10316.2/43293

DOI: $\quad$ DOI:https://doi.org/10.14195/1647-8606_60-2_7

Accessed : $\quad$ 26-Apr-2023 10:27:30

A navegação consulta e descarregamento dos títulos inseridos nas Bibliotecas Digitais UC Digitalis, UC Pombalina e UC Impactum, pressupõem a aceitação plena e sem reservas dos Termos e Condições de Uso destas Bibliotecas Digitais, disponíveis em https://digitalis.uc.pt/pt-pt/termos.

Conforme exposto nos referidos Termos e Condições de Uso, o descarregamento de títulos de acesso restrito requer uma licença válida de autorização devendo o utilizador aceder ao(s) documento(s) a partir de um endereço de IP da instituição detentora da supramencionada licença.

Ao utilizador é apenas permitido o descarregamento para uso pessoal, pelo que o emprego do(s) título(s) descarregado(s) para outro fim, designadamente comercial, carece de autorização do respetivo autor ou editor da obra.

Na medida em que todas as obras da UC Digitalis se encontram protegidas pelo Código do Direito de Autor e Direitos Conexos e demais legislação aplicável, toda a cópia, parcial ou total, deste documento, nos casos em que é legalmente admitida, deverá conter ou fazer-se acompanhar por este aviso.

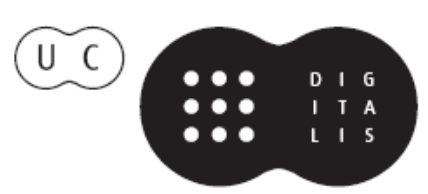




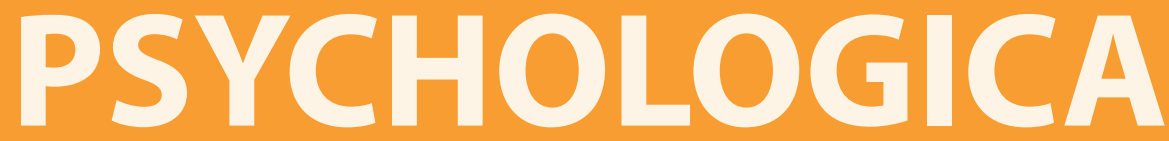




\title{
A Liderança dos Diretores no Contexto Educativo Português: a Ética e a Moral, Quais as Competências e Tendências?
}

\author{
Lurdes Neves ${ }^{1}$ e Joaquim Luís Coimbra ${ }^{2}$
}

Director's leadership in the Portuguese educational context: ethics and morality, what skills and trends

\begin{abstract}
The school, as the basic unit and a space for the achievement of objectives and goals of the education system, is constantly being renovated, becoming a major challenge for the directors, because it requires of them new skills, knowledge, abilities and attitudes that converge in the need of development of skills for making the decisions more participatory and fair. This study goal is to identify in 30 educational directors of school groups, their leadership perceptions and practices. To achieve this goal, a mix study has been carried out using semi-structured interviews and three leadership scales (ethical, moral and transformational). It was found that the leadership perceptions vary between transactional and transformational and that some leadership skills are predictors of the type of leadership exercised.
\end{abstract}

Keywords: directors; education; leadership

1 Faculdade de Psicologia e de Ciências da Educação da Universidade do Porto. Email: pdpsi11006@fpce.up.pt

2 Faculdade de Psicologia e de Ciências da Educação da Universidade do Porto. Email: jcoimbra@fpce.up.pt. 


\section{Resumo}

A escola, como unidade básica e espaço de realização de objetivos e metas do sistema educativo, encontra-se em constante remodelação, tornando-se num grande desafio para os diretores, por exigir deles novas competências, conhecimentos, capacidades e atitudes, que convergem na necessidade de desenvolvimento de competências para a tomada de decisões participativas e justas. Assim, este estudo teve como objetivo conhecer quais as perceções e práticas de liderança exercidas por 30 diretores de Agrupamentos de Escolas. Para alcançar este objetivo, recorreu-se a um estudo misto, tendo sido realizada uma entrevista semiestruturada aos Diretores e aplicadas três escalas de liderança (ética, moral e transformacional). Foi possível constatar perceções de liderança que variam entre o transacional e transformacional e que algumas capacidades do líder são preditoras do tipo de liderança exercida.

Palavras-chave: diretores; educação; liderança

\section{INTRODUÇÃO}

Num contexto atual de procura crescente da qualidade nos sistemas educativos e das aprendizagens dos alunos, de forma a qualificar cada vez mais as pessoas para o mundo do trabalho, têm vindo a proliferar discursos e reformas políticas e curriculares no sentido de gerar uma eficiência crescente, eficácia e qualidade na educação. As mudanças verificadas trouxeram à discussão a questão da liderança como tema central. A partir dessa noção amplificada e com ecos reverberando em amplos espectros da vida em sociedade, existe, no campo educativo, uma constante preocupação com sucesso educativo e gestão participativa, o que pressupõe a tomada de decisão partilhada ao nível das lideranças intermédias e a visão de uma educação básica encarada como responsabilidade por todos.

No atual contexto português emergem as políticas educativas que buscam a qualidade e transparência da educação, num quase-mercado educativo, que se baseia na escolha, cada vez maior, da escola que poderá oferecer um serviço de qualidade; procura-se também a ética e os códigos de valores morais que determinam os comportamentos de liderança, pois influenciam todos os processos de tomada de decisões no contexto educativo.

Com efeito, a gestão dos estabelecimentos de ensino público português tem vindo a apresentar significativas alterações nos últimos anos, que importa registar e estudar. Por um lado, houve um aumento das dimensões físicas, geográficas 
e sociais dos estabelecimentos escolares, que foram agrupados e, nalguns casos, posteriormente agregados. Por outro lado, as competências dos órgãos de gestão estratégica e pedagógica também foram alteradas.

Verifica-se ainda que os rankings das escolas se assumem como um fator explícito do quase-mercado educativo em Portugal, sendo o reflexo da ética dos comportamentos de liderança. Tendem a ser um instrumento de escolha da escola que acaba por influenciar cada vez mais a sua procura e a ser usado por cada escola como agente promotor da procura de práticas pedagógicas que conduzam a melhores resultados por parte dos alunos.

Embora se entenda que o ato educativo é bastante complexo e para o qual confluem inúmeras variáveis, os indicadores dos rankings por si só não refletem a qualidade da aprendizagem dos alunos, nem são responsáveis diretamente pelo sucesso das aprendizagens, não podendo ser estabelecida uma relação direta e causal entre ranking e qualidade da aprendizagem. Na base da construção dos rankings escolares estão indicadores de natureza quantitativa que segmentam a realidade a partir de variáveis relacionadas com os desempenhos individuais dos alunos "quase sempre reduzidas à medida das suas performances cognitivas" (Santiago, Correia, Tavares, \& Pimenta, 2004). Nesta medida, a construção das listas ordenadas de escolas baseia-se nos resultados dos exames nacionais - outputs das escolas - verificando-se, portanto, a ênfase dada à componente cognitiva. Com efeito, no caso português, os rankings de escolas são "reduzidos a um conjunto de indicadores numéricos, que resultam de desempenhos de alunos abstratos, homogéneos e destacados dos seus contextos sociais e culturais de vida" (Santiago et al., 2004). Vários autores explicam os problemas associados à utilização dos indicadores de performance para a elaboração de rankings (Santiago et al., 2004). A esta problemática acresce a reorganização da rede escolar - realizada através da criação dos agrupamentos e a agregação de escolas e que veio garantir e reforçar a coerência do projeto educativo e a qualidade pedagógica das escolas e estabelecimentos de educação pré-escolar que o integram, bem como proporcionar aos alunos de uma dada área geográfica um percurso sequencial e articulado e, desse modo, favorecer a transição adequada entre os diferentes níveis e ciclos de ensino. No que concerne às competências dos órgãos de gestão e do diretor, com o Decreto-Lei n. ${ }^{\circ}$ 137/2012 de 2 de julho, mantêm-se os órgãos de administração e gestão, mas reforça-se a competência do conselho geral, assegurando-se a sua legitimidade, enquanto órgão de representação dos agentes de ensino, dos pais e encarregados de educação e da comunidade local, designadamente de instituições, organizações de caráter económico, social, cultural e científico. Por seu lado, com esta remodelação, o conselho pedagógico é composto exclusivamente por professores, o que lhe confere um caráter estritamente profissional. Com 
o Decreto-Lei n. ${ }^{\circ}$ 137/2012 de 2 de julho, procede-se ainda ao reajustamento do processo eleitoral do diretor, conferindo-lhe maior legitimidade através do reforço da exigência dos requisitos para o exercício da função e, por outro lado, consagrando-se mecanismos de responsabilização no exercício dos cargos de direção, de gestão e de gestão intermédia.

No quadro legal em vigor, as competências do diretor contemplam a responsabilidade pela elaboração e apresentação dos documentos estruturantes da escola ao conselho geral, que os aprova, pela elaboração do plano de formação do pessoal docente e não docente, pela definição do regime de funcionamento do agrupamento, pela avaliação do pessoal docente, no quadro da legislação em vigor (cf. Decreto-Lei n. ${ }^{\circ}$ 137/2012 de 2 de julho). Isto é, o diretor tem a incumbência de representar o estabelecimento, de exercer o poder hierárquico, de garantir a qualidade do ensino e o bom funcionamento dos serviços técnicos e administrativos, de gerir os equipamentos e preservar o património do agrupamento, tudo isto numa lógica de prestação de contas quer ao conselho geral, onde estão representados os atores locais, quer à administração educativa central e local.

De notar que com o Decreto-Lei n. ${ }^{\circ} 115-\mathrm{A} / 98$ de 4 de maio o diretor, ou o presidente do conselho executivo, se a escola optasse por essa modalidade de gestão, era membro do conselho pedagógico, mas não necessariamente o seu presidente. O Decreto-Lei n. ${ }^{\circ} 75 / 2008$ de 22 de julho vem devolver ao diretor a presidência do conselho pedagógico e reconhecer-lhe competências de gestão pedagógica, compreendendo-se que sem as quais estaria sempre limitado nas suas funções. Ao mesmo tempo que se reconhece esta dimensão de atuação, dá-se visibilidade ao cargo e o diretor passa a ser a figura central de representação da escola.

Finalmente, as alterações que têm vindo a acontecer no contexto educativo nomeadamente ao nível da estrutura dos agrupamentos e da criação dos rankings com vista à promoção do sucesso escolar, constituem-se como desafios crescentes às práticas de liderança e gestão utilizadas nestes contextos.

Neste sentido, este estudo tem como objetivo conhecer quais as perceções e práticas de liderança adotadas pelos diretores educativos de 30 agrupamentos de escolas do Norte e Centro do país (liderança transformacional, ética ou moral) e tem como questões de investigação orientadoras do artigo a compreensão de: 1) qual o tipo de liderança exercido pelos diretores (transformacional, ético ou moral); 2) quais as competências percecionadas como necessárias para a liderança; 3) quais as estratégias de promoção da motivação utilizadas no âmbito das suas práticas de liderança; 4) qual a visão que os diretores apresentam da escola; 5) qual a posição dos diretores em relação aos agrupamentos escolares; e 6) qual a posição dos diretores face aos rankings nacionais. 
No que concerne às práticas de liderança adotadas pelos diretores, desenvolve-se de seguida a explicitação de cada um dos tipos de liderança em estudo: liderança transformacional, liderança ética e liderança moral.

\section{Liderança Transformacional}

O conceito de liderança transformacional foi introduzido inicialmente por Burns (1978), referindo-se a determinados líderes políticos que motivavam os seguidores a atingirem maiores níveis de moralidade e motivação. Bass (1985) expandiu este conceito, formulando um modelo em que a liderança transformacional envolve a influência ativa por parte do líder na motivação dos seguidores ao nível das suas atitudes, inspirando-os a alcançarem os objetivos. Este modelo, no presente estudo, aplicado ao contexto educativo pressupõe a existência de quatro componentes principais: carismático, que induz admiração, respeito e confiança nos seus seguidores; motivacional, que potencia os seguidores a atingirem objetivos e metas mais elevadas; estimulação intelectual, que desafia os seguidores a saírem da sua zona de conforto e os encoraja a desenvolverem as suas competências de forma mais criativa; consideração individualizada, ou seja, o respeito pela individualidade e identidade de cada seguidor.

O líder transformacional é, assim, alguém que é respeitado, que inspira confiança, motiva os outros, em suma, um exemplo a seguir. É, por isso, proativo na concretização da sua visão e missão e está atento às necessidades dos seus seguidores, aumentando o grau de compromisso que estes assumem com a organização e a sua performance no alcance das metas (Bass, 1985; Bass, 1990; Avolio, 1999; Avolio \& Bass, 1995). A liderança transformacional compreende, desta forma, a realização do líder concomitante ao sentido de eficácia e competência coletivos, dado que os seguidores parecem obter maior satisfação, envolvimento e compromisso com os objetivos e metas da organização educativa (Castanheira \& Costa, 2011). Desta forma, a liderança transformacional surge como mais positiva na motivação e desempenho dos colaboradores e como alternativa à liderança transacional que se baseia no uso da motivação extrínseca com impacto (Avolio, 1999; Bass, 1998). Por outro lado, os líderes transformacionais "inspiram confiança, buscam desenvolver a liderança em outros, exibem o autossacrifício no sentido do altruísmo e servem como agentes morais, concentrando-se e fazendo com que os seguidores se concentrem em objetivos que transcendam as necessidades mais imediatas do grupo de trabalho" (Dumdum, Lowe, \& Avolio, 2013). Na liderança laissez-faire, o líder demarca-se das suas responsabilidades e autoridade, que os autores consideram tratar-se da "menos potente", num contínuo de comportamentos de liderança, que contrasta 
com a transformacional (a "mais potente") (Bass \& Avolio, 2003). Castanheira e Costa (2011) fizeram uma meta-análise focada na realidade portuguesa, com base na utilização do Multifactor Leadership Questionnaire (Bass \& Avolio, 2003) indicando a predominância do tipo de liderança transformacional e da liderança transacional nas escolas públicas portuguesas.

Dando sustentação a esta proposição, investigações têm revelado que a liderança transacional leva a um desempenho superior quando "aumenta" ou acrescenta à liderança transformacional (Antonakis \& House, 2002). Burns (1978), quando introduz o conceito de liderança transformacional baseado na teoria de desenvolvimento moral de Kohlberg (1976), perspetivava ainda que os líderes poderiam encaminhar os seus seguidores para níveis mais elevados de consciência moral. No entanto, a dimensão moral da liderança transformacional foi seriamente questionada em cada uma das componentes do constructo da liderança transformacional por Bass (1998). De acordo com o autor, apesar de as componentes dos constructos de liderança apresentarem uma dimensão ética e moral, como Bass e Steidlmeier (1999) reconheceram, esta é moralmente neutra.

Adicionalmente, Howell e Avolio (1992) demonstraram que os líderes transformacionais podem agir de forma ética ou antiética, dependendo dos valores imbuídos na sua visão e estratégia, o que justifica a compreensão do conceito de liderança ética e de liderança moral neste estudo e a avaliação da perceção das práticas de liderança ética e moral pelos diretores dos agrupamentos de escola.

\section{Liderança ética}

O conceito de liderança ética diz respeito aos comportamentos do líder que vão ao encontro das crenças e valores morais da organização, particularmente nas organizações éticas que norteiam a sua missão de acordo com os padrões morais vigentes e agem de forma socialmente responsável (Brown, Treviño, \& Harrison, 2005).

$\mathrm{O}$ interesse pela investigação na liderança ética é relativamente recente e tem em conta estes fatores de dimensão cultural e social, que se refletem no comportamento organizacional (Priem \& Shaffer, 2001; Robertson, Crittenden, Brady, \& Hoffman, 2002). Brown et al. (2005) descrevem os líderes éticos como honestos, confiáveis, justos e solidários, norteando as suas atitudes e comportamentos por forma a estruturarem ambientes de trabalho justos. Estes líderes contrastam com os líderes despóticos que colocam os seus interesses à frente dos da organização e apresentam comportamentos autoritários, centrados nos interesses próprios e na exploração dos outros (Aronson, 2001). 


\section{Liderança Moral}

A inteligência moral tem sido definida como a capacidade de distinguir o certo do errado, de possuir fortes convicções morais e de ter comportamentos ajustados. Assim, a inteligência moral refere-se à forma como os princípios universais são aplicados aos nossos valores, objetivos e performance (Lennick \& Kiel, 2011). Convém referir a distinção entre inteligência moral e inteligência emocional, dado que esta última é desprovida de valores e pode ser aplicada "tanto para o bem, como para o mal”, enquanto a inteligência moral é, por definição, e de acordo com os autores direcionada para o bem (Lennick \& Kiel, 2008). Este conceito ganha particular relevância no contexto organizacional, dado que a integridade do líder parece ser um importante preditor do comportamento dos seguidores, da sua motivação, satisfação e investimento (Mamede, Ribeiro, Gomes, \& Rego, 2014; Wayne \& Green, 1993).

Lennick e Kiel (2008) afirmam que os líderes moralmente mais competentes revelam maior consistência nos seus comportamentos e maior alinhamento com os princípios morais, valores e crenças, que resultam em consequências positivas para a organização. Para estes autores, a inteligência moral envolve quatro dimensões: integridade, ou seja, agir de forma consistente com os princípios universais, valores e crenças pessoais, dizer a verdade e defender o que considera certo e manter as promessas; responsabilidade, pelas suas escolhas pessoais, admitindo os seus erros e falhas e assumir a responsabilidade pelos seus seguidores; compaixão, ou seja, preocupar-se com os outros; perdão, ou seja, perdoar os seus erros e falhas e as dos outros.

\section{MÉTODO}

\section{Objetivo}

Este estudo tem como objetivo conhecer as perceções e práticas de liderança exercidas pelos diretores educativos de 30 agrupamentos de escolas do Norte e Centro do país (liderança transformacional, ética ou moral).

\section{Questões de investigação}

O presente estudo tem ainda como questões de investigação a compreensão de: 1) qual o tipo de liderança exercido pelos diretores (transformacional, ético ou 
moral); 2) quais as competências percecionadas como necessárias para a liderança; 3) quais as estratégias de promoção da motivação utilizadas no âmbito das suas práticas de liderança; 4) qual a visão que os diretores apresentam da escola; 5) qual a posição dos diretores em relação aos agrupamentos escolares; e 6) qual a posição dos diretores face aos rankings nacionais.

\section{Procedimento}

As duas formas de inquérito - quantitativa e qualitativa - são frequentemente retratadas como paradigmas distintos e incompatíveis em investigação educacional (Shaffer \& Serlin, 2004). No entanto, reconhecendo-se que diferentes métodos de análise são úteis porque se dirigem para diferentes tipos de questões, começaram-se a utilizar simultaneamente ambos os tipos de técnicas - qualitativas e quantitativas - métodos mistos (Shaffer \& Serlin, 2004; Johnson \& Onwuegbuzie, 2004) pela complementaridade de dados e fontes de informação. No presente estudo, foi adotado o método misto de recolha de dados sendo o estudo I de carácter quantitativo e o estudo II de carácter qualitativo.

Foram enviados convites para os Diretores dos Agrupamentos de Escola da zona Norte e Centro do país para participação no presente estudo, tendo aceitado participar 30 diretores. Estes 30 diretores de agrupamentos escolares foram posteriormente contactados presencialmente, tendo-lhes sido explicados concretamente os objetivos do presente estudo.

O estudo I consistiu na aplicação de três escalas distintas sobre a liderança (ética, moral e transformacional) aos 30 diretores e teve como objetivo compreender qual o tipo de liderança exercido por cada diretor. O estudo II compreendeu a realização de entrevistas semiestruturadas a estes mesmos diretores e teve como objetivos: 1) Descrever as competências percecionadas como necessárias para a liderança pelos diretores; 2) Descrever a visão que os diretores apresentam da escola; 3) Conhecer a posição que os diretores assumem face à criação dos agrupamentos; 4) Conhecer qual a posição dos diretores face aos rankings. A recolha dos dados ocorreu entre março e outubro de 2015.

O recurso a estes dois métodos - questionário e entrevista - foi utilizado para obter a informação necessária para alcançar os objetivos deste estudo. Posteriormente, foram analisados os dados quantitativos e, de seguida, os dados qualitativos.

Para a análise dos dados quantitativos recorreu-se ao Statistical Package for the Social Sciences.

Relativamente aos dados qualitativos, o processo de codificação procurou identificar a relação das perceções dos entrevistados com os temas em análise. Para 
tal, importaram-se todos os dados para o software NVivo e foram criadas categorias de análise. Estas serão representadas através do número de participantes que contribuíram para a cada categoria (fontes) e o número de vezes que a categoria é referenciada (referências).

\section{Instrumentos}

\section{Estudo I - Questionários}

Os diretores responderam aos seguintes questionários: questionário sociodemográfico, o Questionário de Liderança Ética (Neves, Jordão, Cunha, Vieira \& Coimbra, 2016; QLE), o Questionário de Liderança Transformacional (Bass \& Avolio, 2003; QLT) e o Questionário de Liderança Moral (Mamede, Ribeiro, \& Gomes, 2010; QLM).

O questionário sociodemográfico foi aplicado na medida em que é fundamental para uma melhor compreensão da população em estudo, tendo sido recolhida informação sobre a idade, o sexo e o tempo de serviço dos diretores.

O QLE é constituído por 23 itens, cotados numa escala do tipo Likert de 1 a 7 pontos; é usado para avaliar a liderança ética em duas dimensões: liderança ética e despótica. A liderança ética considera o modo como os líderes se devem comportar, contrariamente ao modo como se comportam na prática. A liderança despótica reflete o comportamento autoritário que serve o interesse do próprio líder e se traduz no seu egocentrismo, insensibilidade e exploração de outros.

O QLT é constituído por 45 itens, cotados numa escala do tipo Likert de 0 a 4 pontos; tem como objetivo aferir a frequência com que comportamentos de liderança transformacional, transacional, laissez-faire e resultados da liderança (eficácia, satisfação e esforço extra) são observados pelos seguidores. Neste estudo, só se usaram os 36 itens relativos aos tipos de liderança. Esta escala avalia os seguintes tipos de liderança:

Liderança transformacional - o líder promove a motivação e a mudança de atitudes dos seguidores de forma a inspirá-los para alcançar os objetivos;

Liderança transacional - o líder recorre a um sistema de recompensas e punições em função do cumprimento, ou não, dos objetivos;

Liderança laissez-faire - o líder não evidencia comportamentos de liderança e abdica de tomar decisões e de assumir responsabilidades.

O QLM é constituído por 12 itens, cotados numa escala do tipo Likert de 1 a 5, focados em avaliar a competência moral e emocional do líder. Estas compe- 
tências são avaliadas através de quatro dimensões: integridade, responsabilidade, compaixão e perdão.

\section{Estudo II - Entrevista}

Relativamente à entrevista, recorreu-se a um guião composto por duas partes. A primeira inclui as questões sociodemográficas complementares aos dados recolhidos no questionário dos diretores, nomeadamente a formação académica, formação complementar, experiência na função de diretor e percurso profissional realizado até ao momento. A segunda parte inclui as seguintes questões:

1. O que é para si a liderança de um agrupamento de escolas?

2. Como se vê como líder?

3. Quais são os seus pontos fortes na posição que ocupa?

4. Quais são os seus pontos fracos na posição que ocupa?

5. Quais as competências que considera serem mais importantes num líder educativo?

6. O que pensa das recentes medidas de restruturação da escola pública e de criação dos mega agrupamentos?

7. O que pensa da competição existente entre as escolas, visível na publicação de rankings nacionais?

No que concerne à "orientação para a liderança transformacional” (Leithwood, 1994), contemplaram-se ainda na entrevista as 6 perguntas seguintes:

1. Quais os meios e mecanismos que utiliza para transmitir as práticas e os valores organizacionais mais importantes?

2. Quais os meios utilizados para estabelecer e comunicar os objetivos e resultados escolares e expetativas de desempenho da sua eficácia aos professores e pessoal não docente?

3. De que modo envolve os professores e o pessoal não docente na estratégia da escola e no apoio à tomada de decisão?

4. Quais são os mecanismos que utiliza no agrupamento para promover a motivação e a estimulação da participação e envolvimento dos professores e pessoal não docente?

5. De que forma presta apoio individualizado aos professores e pessoal não docente?

6. Quais as ações que desenvolve junto dos professores e do pessoal não docente para pôr em prática o seu conceito de escola? 


\section{Participantes}

A maioria dos participantes é do sexo masculino, 24 (80.0\%), e com idades entre os 50 e 60 anos, 15 (50.0\%). A nível de experiência profissional na função de diretor ou na direção de escola verifica-se que 5 (16.7\%) dos participantes têm até 15 anos de experiência, 6 (20.0\%) entre 15 e 20 anos, 10 (33.3\%) entre 20 e 25 anos e 9 (30.0\%) mais de 25 anos de experiência. Relativamente à formação académica, observa-se que 1 (3.3\%) participante tem o doutoramento, 15 (50.0\%) têm mestrado e $14(46.7 \%)$ têm licenciatura.

\section{RESULTADOS}

\section{Resultados - Estudo I}

Nesta secção foram verificados os resultados obtidos pelos diretores nas três escalas de liderança, as correlações entre as dimensões avaliadas e se alguma das competências dos diretores (integridade, perdão, responsabilidade e compaixão) é preditor de algum tipo de liderança (ética, despótica, transformacional, transacional e laissez-faire).

Observando a tabela 1 é possível constatar que, em quase todas as medidas, os valores estão acima do ponto médio, com exceção das vertentes menos positivas da liderança despótica e laissez-faire.

É possível apurar que os valores entre sexos são muito similares e, nas dimensões em que estes se apresentam mais diferenciados, não se verificam diferenças estatisticamente significativas.

Tabela 1

Resultados da liderança por sexo

\begin{tabular}{lccc}
\hline & Feminino & Sexo & \\
Média (D. P.) & & $\begin{array}{c}\text { Masculino } \\
\text { Média (D. P.) }\end{array}$ & $\begin{array}{c}\text { Total } \\
\text { Média (D. P.) }\end{array}$ \\
\hline Liderança Ética & & & \\
Ética & $6.39(0.10)$ & $6.29(0.43)$ & $6.31(0.39)$ \\
Despótica & $1.74(0.75)$ & $1.85(0.48)$ & $1.82(0.53)$ \\
\hline
\end{tabular}

Liderança Transformacional

Transformacional

$3.37(0.18)$

$3.24(0.38)$

$3.27(0.35)$ 


\begin{tabular}{llll} 
Transacional & $1.97(0.52)$ & $2.39(0.55)$ & $2.30(0.56)$ \\
Laissez-faire & $0.77(0.21)$ & $0.59(0.43)$ & $0.63(0.40)$ \\
\hline Liderança Moral & & & \\
Integridade & $4.67(0.21)$ & $4.74(0.35)$ & $4.72(0.33)$ \\
Perdão & $4.21(0.19)$ & $4.03(0.55)$ & $4.07(0.50)$ \\
Responsabilidade & $4.78(0.27)$ & $4.78(0.27)$ & $4.78(0.27)$ \\
Compaixão & $3.83(0.52)$ & $4.17(0.58)$ & $4.10(0.58)$ \\
\hline
\end{tabular}

Relativamente às correlações entre as dimensões avaliadas, é possível verificar (cf. tabela 2), ao nível de interescalas, que a maior correlação observada é entre a liderança ética e o perdão (liderança moral) $(\mathrm{r}=.75, \mathrm{p}<.05)$, sendo que valores elevados de liderança ética estão correlacionados com valores elevados de perdão. A nível intraescalas, a correlação mais elevada e positiva encontra-se na liderança moral entre o perdão e a compaixão $(\mathrm{r}=.61, \mathrm{p}<.01)$. Outra correlação de salientar é relativa à liderança despótica, em que é possível verificar que esta se correlaciona negativamente com o perdão $(\mathrm{r}=-.44, \mathrm{p}<.05)$, com a responsabilidade $(\mathrm{r}=$ $-.54, \mathrm{p}<.01)$ e com a compaixão $(\mathrm{r}=-.36, \mathrm{p}<.05)$. Sendo que a valores elevados de liderança despótica estão correlacionados valores baixos de perdão, de responsabilidade e compaixão.

Tabela 2

Correlações de Pearson entre dimensões

\begin{tabular}{llllllllll}
\hline & 1 & 2 & 3 & 4 & 5 & 6 & 7 & 8 & 9 \\
\hline
\end{tabular}

\section{Liderança Ética}

1. Ética

2. Despótica $-.44^{*}$

\section{Liderança Transformacional}

3. Transformacional $\quad .61^{* *}-.35$

4. Transacional $\quad .02 \quad-.03 \quad .08$

5. Laissez-Faire $\quad-.22 \quad .16 \quad-.35 \quad-.14$

Liderança Moral

$\begin{array}{llllll}\text { 6. Integridade } & .15 & -.10 & .19 & .41^{*} & -.17\end{array}$

$\begin{array}{lllllll}\text { 7. Perdão } & .75^{* *} & -.44^{*} & .56^{* *} & -.24 & -.08 & .08\end{array}$

$\begin{array}{lllllllll}\text { 8. Responsabilidade } & .32 & -.54^{* *} & .28 & .42^{*} & -.40^{*} & .19 & .20\end{array}$

$\begin{array}{llllllllll}\text { 9. Compaixão } & .57^{* *} & -.36^{*} & .43^{*} & -.02 & -.17 & -.06 & .61^{* *} & 0.33\end{array}$

p $<.05 ;{ }^{* *} \mathrm{p}<.01$

Procedeu-se a análises de regressão para verificar se as competências dos diretores (integridade, perdão, responsabilidade e compaixão) apresentam efeitos preditivos nos tipos de liderança (ética, despótica, transformacional, transacional e laissez-faire).

Verificou-se que o perdão é um preditor da liderança transformacional, ética e despótica. Mais concretamente, como é possível observar na tabela 3, as regressões 
lineares simples revelaram que o modelo explica $57 \%$ da variância da liderança ética $\left(\mathrm{R}^{2}{ }_{\mathrm{aj}}=.57, \mathrm{p}<.001\right)[\mathrm{F}(1,28)=36.59, \mathrm{p}<.001] ; 19 \%$ da liderança despótica $\left(\mathrm{R}^{2}{ }_{\mathrm{aj}}=.16, \mathrm{p}<.01\right)[\mathrm{F}(1,28)=6.54, \mathrm{p}<.01]$ e $31 \%$ da liderança transformacional $\left(\mathrm{R}^{2}{ }_{\mathrm{aj}}=.28, \mathrm{p}<.001\right)[\mathrm{F}(1,28)=12.50, \mathrm{p}<.001]$. Verificou-se que o perdão é um preditor estatisticamente significativo da liderança ética $(\mathrm{t}=6.05, \mathrm{p}<.001)$, da liderança despótica $(\mathrm{t}=-2.56, \mathrm{p}<.01)$ e da liderança transformacional $(\mathrm{t}=3.54$, $\mathrm{p}<.001)$. Assim, é possível afirmar que quanto maior a capacidade de perdoar, maiores serão os níveis de liderança ética e transformacional e mais baixos os níveis de liderança despótica.

Tabela 3

Regressão linear simples: perdão como preditor da liderança

\begin{tabular}{lcccc}
\hline \multicolumn{5}{c}{ VI: Perdão } \\
\hline VD: & R2 (R2aj.) & $\mathrm{F}(1,28)$ & $\mathrm{b}$ & $\mathrm{t}$ \\
\cline { 2 - 5 } Liderança Ética & $.57(.55)$ & 36.59 & .75 & $6.05^{* * *}$ \\
Liderança Despótica & $.19(.16)$ & 6.54 & -.44 & $-2.56^{\star *}$ \\
Liderança Transformacional & $.31(.28)$ & 12.50 & .56 & $3.54^{* * *}$ \\
\hline
\end{tabular}

VI = Variável Independente; $\mathrm{VD}=$ Variável Dependente; ${ }^{* *} \mathrm{p}<.01 ;{ }^{* * *} \mathrm{p}<.001$

Observando a tabela 4 é possível constatar que o modelo de regressão linear múltipla revelou que a integridade e responsabilidade explicam $29 \%$ da variância da liderança transacional $\left(\mathrm{R}^{2}{ }_{\mathrm{aj}}=.24, \mathrm{p}<.01\right)[\mathrm{F}(2,27)=5.51, \mathrm{p}<.01]$. A integridade $(\mathrm{t}$ $=2.05, \mathrm{p}<.05)$ e a responsabilidade $(\mathrm{t}=2.17, \mathrm{p}<.05)$ são preditores significativos da liderança transacional, sendo que, quanto maiores os valores de integridade e responsabilidade, maiores os níveis de liderança transacional.

Tabela 4

Regressão linear simples: preditores da Liderança Despótica

\begin{tabular}{lcccc}
\hline \multicolumn{5}{c}{ Liderança Transacional } \\
\hline Preditores: & R2 (R2aj.) & F $(2,27)$ & b & $\mathrm{t}$ \\
\cline { 2 - 5 } Integridade & $.29(.24)$ & \multirow{2}{*}{5.51} & .34 & $2.05^{\star}$ \\
Responsabilidade & & & .36 & $2.17^{\star}$ \\
\hline
\end{tabular}
${ }^{*} \mathrm{p}<.05$

\section{Resultados - Estudo II}

$\mathrm{Na}$ análise das entrevistas, foi tido em conta o objetivo de procurar compreender: a) a definição de liderança e perceção do tipo de liderança utilizado; b) as competências que atribuem ao diretor de agrupamentos de escolas; c) a perceção das dimensões da liderança transformacional, mais concretamente da motivação; d) as conceções sobre a visão da escola, a criação de agrupamentos e rankings nacionais. 
A análise das 30 entrevistas revelou uma série de temas/categorias recorrentes. Estas foram representadas através do número de participantes que contribuíram para cada categoria (fontes) e o número de vezes que a categoria é referenciada (referências). No total o número de fontes criadas foram 30 (cada entrevistado correspondeu a uma fonte) e o número de esquemas/ categorias de análise de conteúdo criadas foram 21.

\section{Perceção do tipo de liderança}

Na liderança transformacional verificam-se noções relativas ao trabalho colaborativo, à corresponsabilização das decisões e à liderança partilhada. Na liderança transacional os entrevistados apresentam a ideia de imposição legal e de objetivos determinados externamente. A liderança gestionária é percecionada através de conceitos de decisão individual, hierarquia vertical e limites legais. Relativamente à liderança emocional, esta é relatada com noções de humanização dos espaços e das relações, de maior proximidade relacional e da resolução de conflitos. No que diz respeito à liderança moral, as referências a esta estão relacionadas com os valores expectáveis.

Observando a tabela 5 é possível constatar que a liderança transformacional é a que é apresentada pelo maior número de entrevistados (16 fontes), seguindo-se a liderança transacional enunciada por 11 fontes. No que diz respeito ao número de vezes em que é referido, o tipo de liderança transformacional é também aquele mais frequente, com 29 referências, seguido da liderança transacional e emocional com 15 referências.

Apesar de ser frequente o entrevistado assumir uma perspetiva única sobre o tipo de liderança que preconiza, existem alguns casos em que um mesmo interlocutor faz referências a dimensões que se enquadram em mais do que um tipo de liderança, demonstrando que a categorização pela qual se enquadram as respostas não será do tipo estanque.

Tabela 5

Perceções do tipo de liderança

\begin{tabular}{lcc}
\hline \multicolumn{1}{c}{ Categoria } & Fontes & Referências \\
\hline Liderança transformacional & 16 & 29 \\
Liderança transaccional & 11 & 15 \\
Liderança gestionária & 6 & 10 \\
Liderança emocional & 8 & 15 \\
Liderança moral & 3 & 6 \\
\hline
\end{tabular}




\section{Competências do Diretor}

Relativamente às competências que atribuem ao diretor, estas estão divididas em 5 categorias:

1. Técnicas: competências ao nível técnico incluindo formação inicial, formação e experiência na área administrativa e ainda domínio da área jurídica e legal. A título de exemplo temos a referência da necessidade de "conhecimento técnico, científico, pedagógico, tem que ter uma componente profissional, portanto, no sentido de alguém que se dedique ao trabalho, que seja capaz, que seja, enfim, que demonstre qualidades laborais naquilo que é a sua função no dia-a-dia";

2. Pessoais/Transversais: competências de cariz individual/transversal como a assertividade, capacidade de organização, a responsabilidade, a autonomia, a proatividade, entre outras. Como exemplo, na perceção dos diretores é referida a "Capacidade de discutir diferentes pontos de vista, diferentes opiniões e chegar a consensos e gestão emocional. Capacidade de visão, de coragem e de ver mais além e de forma estratégica. Deve ter a capacidade de autoavaliação, de aprendizagem e de corrigir o que seja necessário alterar”.

3. Relacionais: competências relativas à capacidade de se relacionar com professores, pais e alunos (ex: saber ouvir, interagir, empatia, etc..) exemplificadas por "saber ouvir, reunir, perguntar, conversar, ser ponderado, de ponderar, capacidade de atualização, capacidade de reconhecer as pessoas, capacidade de conduzir, influenciar, direcionar os talentos, tratar todos por igual e com equidade".

4. Liderança: competências associadas à liderança como a definição de objetivos, visão estratégica, gestão de talento, carisma, motivar, influenciar, orientar, entre outras, definido pelos diretores como alguém que "deve saber o que pretende, saber orientar, delegar, capacidade decidir e assumir responsabilidades", "procurar estabelecer objetivos estratégicos e criar expectativas de alto desempenho procurando defender uma cultura de eficácia e a qualidade de serviço público".

5. Valores: competências relativas à identificação com os valores da escola, como por exemplo, o comprometimento, sentido de missão, etc., como se pode ilustrar na perceção dos Diretores em "ter valores e princípios bem definidos, assumir responsabilidades, capacidade de orientar”.

Analisando a tabela 6 é possível observar que todos os entrevistados (30 fontes) mencionaram a relevância das competências pessoais/transversais (43 referências) e de liderança (49 referências). 
Tabela 6

Perceções das competências do Diretor

\begin{tabular}{lcc}
\hline \multicolumn{1}{c}{ Competências } & Fontes & Referências \\
\hline Técnicas & 18 & 22 \\
Pessoais/Transversais & 30 & 43 \\
Relacionais & 24 & 35 \\
Liderança & 30 & 49 \\
Valores & 10 & 13 \\
\hline
\end{tabular}

\section{Perceção de práticas motivadoras}

Para esta análise foi utilizada como matriz de análise a Teoria de Autodeterminação (Gagné \& Deci, 2005). Seguindo esta teoria, a motivação de um indivíduo pode ser analisada em três grupos: desmotivação, motivação extrínseca e motivação intrínseca. A dimensão desmotivação enquanto ausência de motivação, não foi considerada nesta análise pois o objetivo era analisar conceções e práticas relativas à motivação. A motivação extrínseca está repartida em quatro dimensões: I) regulação externa, o indivíduo age em troca de recompensas ou para evitar punições; II) regulação introjetada, o indivíduo regula as consequências externas em função de pressões internas como os seus sentimentos; III) regulação identificada, mais autónoma que as anteriores, o indivíduo apresenta alguma interiorização, mas a motivação continua sendo externa/instrumental; IV) regulação integrada, o indivíduo apresenta coerência entre o comportamento, objetivos e valores, mas o foco continua na obtenção de benefícios pessoais. Finalmente, relativamente à motivação intrínseca, o indivíduo executa a ação por interesse e prazer na realização desta.

Analisando a tabela 7 é possível constatar que os métodos promotores da motivação utlizados centram-se em técnicas que promovem a motivação extrínseca, mais concretamente, a regulação introjetada (30 fontes, 35 referências) como é exemplo "participamos em imensos projetos, naqueles que o município também organiza, e tentamos convencer os professores a envolver-se devagarinho, e eles vão-se envolvendo devagarinho" e a regulação identificada (22 fontes, 25 referências), sendo exemplo de estratégias de motivação o coaching: "falou para os professores todos e disse-lhes o que é que um professor deve fazer e o que é que pode evitar, fantástico, pô-los a pensar um bocado, há muitas técnicas, não é, de motivar, ele veio para a motivação, veio motivá-los”. 
Tabela 7

Perceções da motivação

\begin{tabular}{lcc}
\hline \multicolumn{1}{c}{ Categoria } & Fontes & Referências \\
\hline Motivação Extrínseca & & \\
Regulação Externa & 19 & 23 \\
Regulação Introjetada & 30 & 35 \\
Regulação Identificada & 22 & 25 \\
Regulação Integrada & 6 & 6 \\
Motivação Intrínseca & 8 & 9 \\
\hline
\end{tabular}

\section{Conceções sobre a visão escola}

No que se refere às conceções da visão da escola, as ideias encontram-se repartidas por três categorias:

1. Escola inclusiva: ideias que remetem para a escola como elemento de inclusão social e promotora de igualdade, focada no apoio aos alunos e famílias mais carenciadas e marginalizadas. Uma escola com uma missão social e promotora da igualdade como é exemplo: "Falo em escola inclusiva porque sempre tivemos alunos de todos os estratos sociais, se é que isso agora interessa, e com todas as valências, desde os meninos com deficiência ao nível motor, ao nível cognitivo também, desde surdos, cegos, já tivemos alunos autistas (...) dificilmente consegue distinguir um aluno surdo dum aluno não surdo, os de cadeiras de rodas obviamente que são facilmente são distinguidos (...) e são tão acarinhados quer por professores, quer por auxiliares";

2. Desenvolvimento humano: conceções da escola como um local para o desenvolvimento humano, focado não só nas competências técnicas, mas também nas competências sociais e culturais de todos os intervenientes (pais, alunos e professores), de que é exemplo "as direções de escola, dos agrupamentos, os diretores de turma têm cada vez mais responsabilidades - porque depois não é só uma responsabilidade profissional, é quase uma responsabilidade moral, que as pessoas sentem esses miúdos como seus";

3. Organização produtiva: uma visão da escola como uma organização prestadora de serviços, focada em seguir diretrizes, no cumprimento de objetivos e na qualidade dos serviços prestados. A título de exemplo consideramos que "Quando um professor diz, quando se refere "à minha escola”, é sinal que está envolvido com a escola, portanto, esse professor é uma mais-valia para o trabalho que se desenvolve na escola (...) Portanto, nós temos que estar em grupo, envolvidos, e esta é que é uma mais-valia para que se consigam os objetivos que temos propostos [na escola]". 
Observando a tabela 8 é possível constatar que todos os entrevistados apresentam visões complexas, em que englobam as 3 categorias. Contudo, a visão da escola como local de inclusão foi a mais referenciada (76 referências).

Tabela 8

Conceções da escola.

\begin{tabular}{lcc}
\hline \multicolumn{1}{c}{ Categorias } & Fontes & Referências \\
\hline Escola Inclusiva & 30 & 76 \\
Desenvolvimento humano & 30 & 35 \\
Organização produtiva & 30 & 38 \\
\hline
\end{tabular}

\section{Conceções sobre a criação de agrupamentos e dos rankings nacionais}

Relativamente à criação de agrupamentos e dos rankings nacionais, os entrevistados apresentaram argumentos a favor ou contra estas medidas.

No que diz respeito aos agrupamentos, observa-se uma maior oposição à criação de agrupamentos ( 22 fontes, 46 referências) do que a favor ( 8 fontes, 17 referências) (cf. com tabela 9). Os entrevistados que estão contra os agrupamentos apresentam argumentos centrados com a perda de proximidade, a um aumento dos conflitos, uma diminuição da qualidade e a racionalização de recursos, de que é exemplo o discurso "uma das desvantagens dos mega agrupamentos é a perda da relação de proximidade do que temos atualmente, aumentando o anonimato e reduzindo a proximidade afetiva com os alunos. Quanto maior o número de intervenientes, maior a probabilidade de conflitos entre alunos, entre alunos e professores e entre professores"; sendo uma escola mais pequena, existe um número limitado de professores e estamos limitados na escolha de lideranças. Como refere o diretor J. A.: "nos mega agrupamentos as escolhas são mais diversificadas e haveria um maior leque de professores. Os mega agrupamentos têm este tipo de conflitos e perda de individualidade. Por seu lado, os que estão a favor recorrem a argumentos focados na rentabilização e adequação dos recursos e na maior proximidade entre alunos, como exemplifica o diretor J.: “fazem sentido algumas agregações em que nitidamente não havia massa crítica de pessoas suficiente (pessoal auxiliar) e era preciso juntar, era preciso criar dimensão, para se poder ter uma densidade de intervenção pedagógica capaz". Relativamente aos rankings nacionais, existe uma maior desaprovação pelos diretores (23 fontes, 47 referências) que a aprovação (7 fontes, 15 referências). A favor encontramos argumentos centrados na transparência entre escolas, a promoção da imagem positiva da escola e a influência para a melhoria de resultados. O diretor A. V. ressalva ainda a "valorização dos rankings como instrumento de trabalho, que não é o instrumento de trabalho que 
os pais recebem" e para além disso "Os rankings são positivos. Porquê? Porque, se calhar, antes de terem sido feitas as publicações dos primeiros rankings ninguém se preocupava muito com o que se passava com os alunos. E, neste momento, cria-se um holofote em cima dos resultados dos exames nacionais"; para além disso "os rankings obrigaram as escolas a utilizar metodologias de acompanhamento dos resultados escolares".

$\mathrm{Na}$ posição contra observaram-se razões focadas na descontextualização dos resultados, em que não existe uma consideração ao tipo de escola (privada vs pública), nas diferenças sociais e nos diferentes critérios utilizados a nível intra e interescola. Para além disso, "rapidamente se confundem rankings de resultados de exames com rankings das escolas e as escolas podem não estar, de todo, sequer bem representadas por esses rankings, por exemplo, as escolas que têm uma oferta formativa diversa (...) que não são sujeitas a exames nacionais e portanto logo aí uma parte, uma grande parte dos seus resultados não está refletida”. O diretor A. O. salienta ainda que "os rankings deviam ser contextualizados, pois as realidades são completamente distintas umas das outras, uma aldeia, ou várias aldeias, ou seja, uma escola do interior muito provavelmente vai ter outro tipo de condições que não terá uma escola do centro de uma cidade”.

Tabela 9

Perceções relativas aos agrupamentos e rankings nacionais

\begin{tabular}{lcc}
\hline & Fontes & Referências \\
\hline Criação de Agrupamentos & & \\
Favor & 8 & 17 \\
Contra & 22 & 46 \\
\hline Rankings Nacionais & & \\
Favor & 7 & 15 \\
Contra & 23 & 47 \\
\hline
\end{tabular}

\section{DISCUSSÃO DE RESULTADOS}

Este estudo centrou-se numa população de diretores de agrupamentos de escolas portuguesas, com o objetivo de analisar quais as perceções dos diretores de agrupamentos de escolas acerca dos seus comportamentos e práticas de liderança.

Relativamente à perceção do tipo de liderança, foi possível verificar que os participantes apresentam níveis acima do ponto médio em todos os tipos de liderança avaliados. Contudo, a perceção que os participantes têm das suas práticas como líderes e do seu tipo de liderança centraram-se mais na liderança transformacional 
e transacional, sendo estas as que apresentaram uma maior frequência. Estes dados vão ao encontro dos encontrados na meta-análise de Castanheira e Costa (2011) em que a perceção dos líderes vai no sentido de se considerarem na dualidade da liderança transformacional e transacional, não tendo em conta a dimensão moral e ética da liderança. A dimensão transformacional estará, assim, relacionada com o conceito de liderança colegial e da possibilidade de eleição da direção enquanto a dimensão transacional está relacionada com o facto de a gestão da escola ser regulada pelo Ministério da Educação.

No que diz respeito às práticas promotoras da motivação, observou-se que estas se concentram, essencialmente, em práticas promotoras da motivação externa, mais concretamente, da regulação introjetada e identificada. À semelhança do que se verifica em outros estudos (Antonakis \& House, 2002; Dumdum, Lowe, \& Avolio, 2013), constatou-se que a perceção que os diretores têm acerca dos seus comportamentos de liderança oscila entre o estilo transacional e o transformacional. Quanto aos comportamentos promotores de motivação, destacam-se os comportamentos percecionados pelos diretores relativos à motivação extrínseca. Acresce que, na perceção dos diretores, as práticas que promovem a motivação intrínseca são as que apresentam menor frequência como estratégias desenvolvidas pelos diretores dos agrupamentos. Segundo os diretores, as práticas de liderança indutoras de motivação intrínseca são percebidas como sendo as menos utilizadas.

No que diz respeito às competências dos líderes, constatou-se que as competências de liderança pessoais/transversais e relacionais são as mais referenciadas pelos entrevistados, tendo em conta que os diretores sentem que são essas competências as que lhes são mais exigidas no exercício do cargo de diretor, para além das competências técnicas e de carácter burocrático e legal. Esta informação vai ao encontro dos resultados das análises de regressão, onde se verificou que competências como o perdão, a responsabilidade e a integridade têm um efeito preditor na liderança, mais especificamente, na liderança transacional e ética.

$\mathrm{O}$ estudo incidiu sobre as competências do diretor do agrupamento, confirmando o que a literatura sobre gestores, nomeadamente sobre gestores escolares (Barroso, 2005; Barrère, 2007; Horng Klasik, \& Loeb, 2009), regista sobre o carácter multifacetado do cargo.

Os resultados obtidos poderão enquadrar-se na perspetiva de Barroso (2005) que defende quatro conceções do gestor, apontando para o carácter multifacetado da gestão escolar: conceção burocrática, conceção gerencialista, conceção corporativa de primus inter pares, conceção político-social, mas com maior incidência para as duas últimas conceções em concreto. Com efeito, qualquer diretor, independentemente do seu estilo de liderança, parece ter de lidar com públicos distintos, o que o impele a agir em função de diferentes modelos de gestão, mesmo que não 
se identifique com todos eles ou com nenhum deles em particular. O diretor é um instrumento da administração central para impor a regulação externa à escola. Pelo contrário, os seus pares esperam que o diretor seja o chefe que os representa e proteja perante a tutela; veem-no como o garante dos seus direitos profissionais e da sua missão pedagógica, assumindo-o como o intermediário entre a escola e a administração central. Nesta conceção corporativa de primus inter pares podemos integrar o segundo fator que afeta a ação do diretor - a sua relação com os pares.

Finalmente, a conceção político-social, em que o gestor surge como o mediador entre os interesses que se cruzam e coexistem na escola - gerir as relações com os pais, alunos, professores, funcionários, comunidade local, gerir inclusivamente a relação da direção com os órgãos de gestão estratégica e pedagógica do agrupamento - acaba por se constituir ela própria como um fator que afeta a ação do diretor. É neste nível de atuação que a regulação interna se torna evidente e podemos tentar perceber a ação estratégica da escola e do seu diretor, mas também como se conciliam estas conceções e modos de ação no seu quotidiano.

Relativamente à visão que têm da escola, foi possível constatar que todos os participantes idealizam a escola como um local para a inclusão e promoção da igualdade, focada no apoio aos alunos e às famílias mais carenciadas e marginalizadas. Também se observou uma visão da escola como um local de desenvolvimento humano e como uma organização centrada nos serviços. Apesar disso, a visão da escola como um local para a inclusão foi a mais referenciada sobretudo nos diretores que adotam a liderança transformacional, ética e moral (nas suas várias dimensões).

No que diz respeito aos temas sobre agrupamentos e rankings nacionais, observou-se que a maioria dos participantes se opõe a ambas as medidas. Verifica-se uma oposição contra a constituição dos agrupamentos escolares baseada no argumento de que estes vão criar uma perda de proximidade com os alunos e com o pessoal docente e não docente, assim como um aumento dos conflitos entre alunos, pais e professores e pessoal não docente, constituindo apenas uma racionalização de recursos humanos. Quanto aos rankings nacionais, a opinião da maioria dos participantes é de que estes são descontextualizados quer da oferta formativa quer, em alguns casos, da realidade de cada uma das escolas. Acrescentam que aqueles não têm em consideração as diferenças sociais de origem dos alunos e da escola, os tipos de escola e os diferentes critérios utilizados a nível intra e interescolar, que poderão não ser comparáveis, pois as ofertas de cada escola são diferenciadas. Acresce que existem escolas em que, pelo menos, 30 a $40 \%$ dos seus alunos estão incluídos noutras ofertas formativas que não são sujeitas a exames nacionais, pelo que uma grande parte dos seus resultados não se encontra refletida nos rankings (Santiago, Correia, \& Tavares, 2004). A opinião dos inquiridos vai ao encontro da manifestada por Santiago, Correia e Tavares (2004), segundo a qual no ato 
educativo confluem inúmeras variáveis e que os indicadores dos rankings por si só não indicam a qualidade da aprendizagem dos alunos, não podendo, por isso, ser estabelecida uma relação direta e causal entre rankings e resultados dos alunos refletidos nas classificações obtidas pelos mesmos. Sendo os rankings escolares centrados, quase exclusivamente, em indicadores quantitativos da performance cognitiva e individual dos alunos, verifica-se que não existe margem para outras variáveis que afetam o ato educativo e a sua qualidade.

Em suma, este estudo ressalva a necessidade de mais estudos com esta população, ainda que com outras amostras de líderes de outros agrupamentos, de forma a ser possível a comparação geográfica e a inferir quanto à implementação de estratégias de liderança diferenciadoras em cada agrupamento.

É de salientar que este estudo teve limitações, à semelhança do que acontece com qualquer outro estudo desta natureza. Primeiramente, a amostra é reduzida, apesar de, na parte qualitativa, esta ter apresentado uma descrição detalhada de cada uma das categorias em análise em função de cada fonte; no estudo quantitativo, o número reduzido de participantes limitou as análises efetuadas. Em segundo lugar, as medidas utilizadas são todas de autorrelato, o que impossibilitou o contraste e a validação dos dados obtidos com informações provenientes de fontes externas. Em terceiro lugar, não foi avaliado o efeito da dimensão do agrupamento a cargo por cada diretor nas suas práticas de liderança. Tendo em conta que esta reorganização de agrupamentos consolida as políticas de concentração de recursos, as estratégias a adotar poderão não ser unanimemente aceites em função da dimensão da organização escola/escolas que dirigem. Em futuros estudos será pertinente avaliar o efeito da estrutura e da dimensão do agrupamento no tipo de liderança e na diversificação das práticas de liderança.

Finalmente, considera-se a pertinência e a relevância do presente estudo na redefinição e na avaliação das práticas de liderança do diretor em cada agrupamento e na melhoria dos processos de tomada de decisões no contexto educativo.

\section{REFERÊNCIAS}

Antonakis, J., \& House, R. J. (2002). An analysis of the full-range leadership theory: The way forward. In B. J. Avolio \& F. J. Yammarino (Eds.), Transformational and charismatic Leadership: The road ahead (pp. 3-33). Amsterdam: Elsevier Science/JAI. doi:10.1108/ S1479-357120130000005006

Aronson, E. (2001). Integrating leadership styles and ethical perspectives. Canadian Journal of Administrative Sciences/Revue Canadienne des Sciences de l'Administration, 18(4), 244-256. doi:10.1111/j.1936-4490.2001.tb00260.x 
Avolio, B. J. (1999). Full leadership development: Building the vital forces in organizations. London: Sage Publications.

Avolio, B. J., \& Bass, B. M. (1995). Individual consideration viewed at multiple levels of analysis: A multi-level framework for examining the diffusion of transformational leadership. Leadership Quarterly, 6(2), 199-218. doi:10.1016/1048-9843(95)90035-7

Barrère, A. (2007). Taches et temporalités. In A. Barrère (ed.), Sociologie des chefs d'établissement: les managers de la République (pp. 41-69). Paris: PUF.

Barroso, J. (2005). Os Gestores Escolares. In J. Barroso, Políticas Educativas e Organização Escolar (pp. 145-171). Lisboa: Universidade Aberta.

Bass, B. M. (1985). Leadership and performance beyond expectation. New York: Free Press. doi:10.1002/ hrm.3930250310

Bass, B. M. (1990). From transitional to transformational leadership: Learning to share the vision. Organizational Dynamics, 18(3), 19-31. doi:10.1016/0090-2616(90)90061-s

Bass, B. M. (1998). Transformational leadership: Industrial, military, and educational impact. Mahwah, N.J.: Lawrence Erlbaum Associates. doi:10.1177/107179199900500317

Bass, B. M., \& Avolio, B. J . (2003). MLQ Multifactor Leadership Questionnaire. Redwood City: Mind Garden. doi:10.1037/t03624-000

Bass, B.M., \& Steidlmeier, P. (1999). Ethics, character, and authentic transformational leadership behavior. Leadership Quarterly, 10(2), 181-217. doi:10.1016/s1048-9843(99)00016-8

Brown, M., Treviño, L., \& Harrison, D. (2005). Ethical leadership: A social learning perspective for construct development and testing. Organizational Behavior and Human Decision Processes, 97(2), 117-134. doi:10.1016/j.obhdp.2005.03.002

Burns, J. M. (1978). Leadership. New York: Harper \& Row. doi:10.2307/1955659.

Castanheira, P., \& Costa, J. (2011). In search of transformational leadership: A (meta) analysis focused on the Portuguese reality. Procedia Social and Behavioral Sciences, 15, 2012-2015. doi:10.1016/j. sbspro.2011.04.045.

Decreto lei n. ${ }^{\circ} 115-A / 98$ de 4 de Maio. I SÉRIE-A. Lisboa: Ministério da Educação e da Ciência.

Decreto lei n. ${ }^{\circ} 75-A / 2008$ de 22 de Abril. I SÉRIE-A. Lisboa: Ministério da Educação e da Ciência.

Decreto lei n.o 137/2012 de 2 de julho. Diário da República n. ${ }^{\circ}$ 126, 1. a serie. Lisboa: Ministério da Educação e da Ciência.

Dumdum, U., Lowe, K., \& Avolio, B. J. (2013). A Meta-Analysis of Transformational and Transactional Leadership Correlates of Effectiveness and Satisfaction: An Update and Extension. In Bruce J. Avolio, Francis J. Yammarino (eds.), Transformational and Charismatic Leadership: The Road Ahead 10th Anniversary Edition (Monographs in Leadership and Management, Volume 5) (pp. 39-70). United Kingdom: Emerald Group Publishing Limited. doi:10.1108/ S1479-357120130000005008

Gagné, M., \& Deci, E. L. (2005). Self-determination theory and work motivation. Journal of Organizational Behavior, 26(4), 331-362. doi:10.1002/job.322

Horng, E.L, Klasik, D., Hasik, D., \& Loeb, S. (2009). Principal time-use and school effectiveness. Stanford: Institute for Research on Education Policy \& Practice. http://web.stanford.edu/ sloeb/ papers/Principal\%20Time-Use\%20(revised).pdf: [Consultado em 30. 07.2017]

Howell, J. M., \& Avolio, B. J. (1992). The ethics of charismatic leadership: Submission or liberation? Academy of Management Executive, 6(2), 43-54. doi:10.5465/ame.1992.4274395

Johnson, R. B., \& Onwuegbuzie, A. J. (2004). Mixed methods research: A research paradigm whose time has come. Educational Researcher, 33(7), 14-26. 
Kohlberg, L. (1976). Moral stages and moralization: The cognitive-developmental. In T. Lickona (ed.), Moral development and behavior: Theory, research and social issues (pp. 31-53). New York: Holt, Rinehart and Winston.

Leithwood, K. (1994). Leadership for school restructuring. Educational administration quarterly, 30(4), 498-518. doi:10.1177/0013161X94030004006

Lennick, D., \& Kiel, F. (2008). Moral Intelligence: Enhancing Business Performance and Leadership Success. New Jersey: Wharton School Publishing. doi:10.1002/hrdq.1171

Lennick, D., \& Kiel, F. (2011), Moral Intelligence 2.0: Enhancing Business Performance and Leadership Success in Turbulent Times. Boston, EUA: Pearson Prentice Hall doi:10.5860/choice.49-2165.

Mamede, C., Ribeiro, N., \& Gomes, D. (2010). Tradução e validação do Moral Competency Inventory para avaliação do grau de Inteligência Moral de líderes. Livro de atas da Conferência em Investigação e Intervenção em Recursos Humanos, Escola Superior de Ciências Empresariais, Instituto Politécnico de Setúbal, 23 e 24 de Setembro, Setúbal.

Mamede, C., Ribeiro, N., Gomes, D., \& Rêgo, A. (2014). Leader's moral inteligence and employees' affective commitment: the mediating role of transformational leadership. XXIV Jornadas Luso Espanholas de Gestão Científica. 6,7 e 8 de Fevereiro de 2014, Leiria: ESTG-IPL.

Neves, L., Jordão, F., Coimbra, J., \& Vieira, D. (2016). Estudo de adaptação e validação de uma escala de perceção de liderança ética para líderes portugueses. Revista Análise Psicológica. 34(2), 165-176

Priem, R., \& Shaffer, M. (2001). Resolving moral dilemmas in business: a multicountry study. Business and Society, 40(2), 197-219. doi:10.1177/000765030104000204

Robertson, C. J., Crittenden, W., Brady, M. K., \& Hoffman, J. J. (2002). Situational ethics across borders: a multicultural examination. Journal of Business Ethics, 38(4), 327-338. doi:10.1023/A:1016067231599

Santiago, R., Correia, F., Tavares, O., \& Pimenta, C. (2004). Um Olhar Sobre os Rankings. Coimbra/ Matosinhos: Centro de Investigação de Políticas do Ensino Superior/ Fundação das Universidades Portuguesas.

Shaffer, D. W., \& Serlin, R. C. (2004). What good are statistics that don't generalize? Educational Researcher, 33(9), 14-25. doi:10.3102/0013189X033009014

Wayne, S. J., \& Green, S. A. (1993). The effects of leader-member exchange on employee citizenship behavior and impression management behavior. Human Relations, 46(12), 1431-1440. doi:10.1177/001872679304601204 